\title{
Supporting Information for: Modeling strain distribution at the atomic level in doped ceria films with extended X-ray absorption fine structure spectroscopy
}

Olga Kraynis $^{1}$, Janis Timoshenko ${ }^{2}$, Jiahao Huang ${ }^{2}$, Harishchandra Singh ${ }^{2}$, Ellen Wachtel ${ }^{1}$, Anatoly I. Frenkel ${ }^{2}$ and Igor Lubomirsky ${ }^{l}$

${ }^{1}$ Department of Materials and Interfaces, Weizmann Institute of Science, Rehovot 76100, Israel

${ }^{2}$ Department of Materials Science and Chemical Engineering, Stony Brook University, Stony Brook, NY 11794, USA

*Email address for correspondence: olgakray@weizmann.ac.il; olgakraynis@gmail.com

\section{A. Film details and XRD parameters}

Table S1: Film details and XRD data (Uncertainty of the last digit is given in parentheses). Parameters are listed as follows: Doped ceria film thickness (nm); Adhesion layer, Al or Ti (See discussion above); below contains film details and X-ray diffraction (XRD) data for all $x$ SDC and $x$ YDC films ( $x$ here is doping fraction in percent) as well as data for $\mathrm{CeO}_{2}$ powder control sample from Clark et al. (ref [54] in main text). It is important to note, films deposited on Ti are known to accumulate larger deposition strain. To relieve some of it, they were additionally annealed after deposition, in the deposition chamber, by heating the sample holder to $400^{\circ} \mathrm{C}$ at $10 \mathrm{mTorr} \mathrm{O}_{2}$ pressure for $4 \mathrm{hrs}$.

Table S1: Film details and XRD data (Uncertainty of the last digit is given in parentheses). Parameters are listed as follows: Doped ceria film thickness (nm); Adhesion layer, Al or Ti (See discussion above); dopant fraction $x$; vacancy fraction $x / 4$; In plane lattice parameter $a^{\|}$; Out-of-plane lattice parameter $a^{\perp}$; The lattice parameter $a$ anisotropy $\left(a^{\perp}-a^{\|}\right) / a^{\perp} \cdot 100 \% ;$ Average lattice parameter $a_{a v}=\left(a^{\|^{2}} \cdot a^{\perp}\right)^{1 / 3}$; First and second shell interatomic distances derived from $a_{a v}$ as follows: (a) $R_{X R D}^{c a t-O}=a_{a v} \cdot \frac{\sqrt{3}}{4} ; \quad$ (b) $R_{X R D}^{c a t-c a t}=a_{a v} \cdot \frac{1}{\sqrt{2}} ; \quad$ (c) $R_{X R D}^{O-O}=a_{a v} \cdot \frac{1}{2}$.

\begin{tabular}{|c|c|c|c|c|c|c|c|c|c|c|c|}
\hline Sample & $\begin{array}{l}\text { Thickness } \\
(\mathbf{n m})\end{array}$ & $\begin{array}{l}\text { Adhesion } \\
\text { layer }\end{array}$ & $\begin{array}{c}\text { Dopant } \\
x\end{array}$ & $\begin{array}{c}\text { Vacancy } \\
x / 4\end{array}$ & $\boldsymbol{a}^{\|}(\AA)$ & $a^{\perp}(\AA)$ & $\begin{array}{l}\text { anisotropy } \\
\text { in } a\end{array}$ & $\boldsymbol{a}_{\boldsymbol{a} v}(\AA)$ & $R_{X R D}^{c a t-o}(\AA)$ & $R_{X R D}^{c a t-c a t}(\AA)$ & $\left.R_{X R D}^{O-O}(\AA)\right)$ \\
\hline $\mathrm{CeO}_{2}$ & Pellet & & & & & & & 5.411(1) & $2.3430(1)$ & $3.8261(7)$ & $2.7055(5)$ \\
\hline 5YDC & 500 & $\mathrm{Ti}$ & $0.05(1)$ & $0.01(1)$ & $5.441(7)$ & $5.445(7)$ & $0.0(2)$ & $5.442(5)$ & $2.356(2)$ & $3.848(3)$ & $2.721(2)$ \\
\hline 10YDC & 700 & $\mathrm{Al}$ & $0.09(1)$ & $0.02(1)$ & $5.397(4)$ & $5.436(4)$ & $0.7(1)$ & $5.410(3)$ & $2.343(1)$ & $3.825(2)$ & $2.705(2)$ \\
\hline 15YDC & 350 & $\mathrm{Ti}$ & $0.14(1)$ & $0.04(1)$ & $5.395(5)$ & $5.429(5)$ & $0.6(1)$ & $5.406(4)$ & $2.341(2)$ & $3.823(2)$ & $2.703(2)$ \\
\hline 20YDC & 350 & $\mathrm{Ti}$ & $0.21(1)$ & $0.05(1)$ & $5.389(7)$ & $5.433(7)$ & $0.8(2)$ & $5.404(6)$ & $2.340(3)$ & $3.821(4)$ & $2.702(3)$ \\
\hline 5SDC & 1200 & $\mathrm{Al}$ & $0.04(1)$ & $0.01(1)$ & $5.421(3)$ & $5.426(3)$ & $0.1(1)$ & $5.423(3)$ & $2.348(1)$ & $3.835(2)$ & $2.711(1)$ \\
\hline 10SDC & 600 & $\mathrm{Ti}$ & $0.09(1)$ & $0.02(1)$ & $5.438(4)$ & $5.457(3)$ & $0.3(1)$ & $5.444(3)$ & $2.357(1)$ & $3.850(2)$ & $2.722(1)$ \\
\hline 15SDC & 500 & $\mathrm{Ti}$ & $0.16(1)$ & $0.04(1)$ & $5.48(1)$ & $5.43(1)$ & $0.8(1)$ & $5.45(1)$ & $2.360(4)$ & $3.853(7)$ & $2.724(5)$ \\
\hline 20SDC & 500 & $\mathrm{Ti}$ & $0.19(1)$ & $0.05(1)$ & $5.46(1)$ & $5.51(1)$ & $0.9(4)$ & $5.47(1)$ & $2.369(4)$ & $3.868(7)$ & $2.735(5)$ \\
\hline
\end{tabular}




\section{B. Comparing data acquired at different synchrotron facilities}

Three films were measured at both SSRL and APS facilities in order to ensure the comparability of samples measured only at SSRL to samples measured only at APS. First shell distances $R_{E X A F S}^{c a t-O}$ for 15SDC, 15YDC and 15GDC (an additional control sample), for both dopant (Do) and Ce edges are given in the figure below. The data were fitted using conventional EXAFS technique (FEFF and Artemis software as described in the main text). No deviation beyond given error bars was recorded, and comparison between facilities is thus considered reliable.

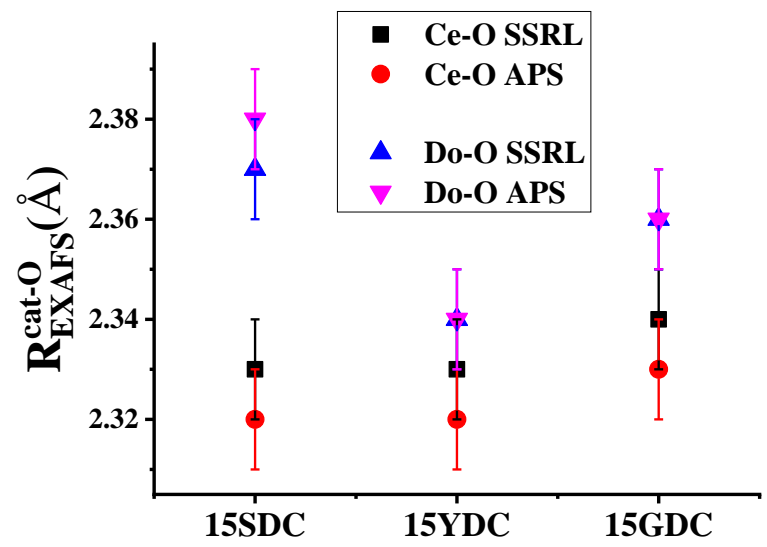

Figure S1: Comparing first shell distances for Ce-O and Do-O acquired at APS and SSRL synchrotron facilities for the same sample. The test was done for three samples: 15SDC, 15YDC (data used in main text) and an additional 15GDC sample. No changes outside the error margins were observed between the two facilities for the same acquired inter atomic distance.

\section{EXAFS first shell (1NN) conventional analysis and RMC results}

Table S2: First shell distances $R$ and disorder factors $\sigma^{2}$ derived using conventional EXAFS (Artemis) analysis, and from RMC-EXAFS, along with the R-factor of the fittings. The uncertainty of the last digit is given in parentheses.

\begin{tabular}{|c|c|c|c|c|c|c|c|c|c|c|c|c|c|c|}
\hline \multirow[t]{2}{*}{ Film } & \multicolumn{6}{|c|}{ Conventional analysis } & \multicolumn{8}{|c|}{ RMC-EXAFS } \\
\hline & $\begin{array}{c}\boldsymbol{R}^{C e-\boldsymbol{O}} \\
(\AA)\end{array}$ & $\begin{array}{c}\sigma^{2} \\
\left(\AA^{2}\right)\end{array}$ & R-factor & $\begin{array}{c}\boldsymbol{R}^{\boldsymbol{D o}-\boldsymbol{O}} \\
(\AA))\end{array}$ & $\begin{array}{c}\sigma^{2} \\
\left(\AA^{2}\right)\end{array}$ & R-factor & $\begin{array}{c}\boldsymbol{R}^{C e-\boldsymbol{O}} \\
(\AA)\end{array}$ & $\begin{array}{c}\sigma^{2} \\
\left(\AA^{2}\right)\end{array}$ & $\begin{array}{c}\boldsymbol{R}^{\boldsymbol{D o}-\boldsymbol{O}} \\
(\AA)\end{array}$ & $\begin{array}{c}\sigma^{2} \\
\left(\AA^{2}\right)\end{array}$ & $\begin{array}{c}\boldsymbol{R}^{\boldsymbol{C e}-\boldsymbol{V}_{o}} \\
(\AA \AA)\end{array}$ & $\begin{array}{c}\sigma^{2} \\
\left(\AA^{2}\right)\end{array}$ & $\begin{array}{c}\boldsymbol{R}^{\boldsymbol{D o}-\boldsymbol{V}_{o}} \\
(\AA \AA)\end{array}$ & $\begin{array}{c}\sigma^{2} \\
\left(\AA^{2}\right)\end{array}$ \\
\hline $\mathrm{CeO}_{2}$ & & & & & & & $2.33(1)$ & - & & & & & & \\
\hline $5 Y \mathrm{YDC}$ & $2.339(9)$ & $0.010(1)$ & 0.020 & $2.36(1)$ & $0.008(2)$ & 0.020 & $2.33(1)$ & $0.008(1)$ & $2.36(1)$ & $0.006(1)$ & $2.40(1)$ & $0.002(1)$ & $2.34(3)$ & - \\
\hline 10YDC & $2.325(7)$ & $0.009(1)$ & 0.016 & $2.35(1)$ & $0.011(2)$ & 0.020 & $2.32(1)$ & $0.009(1)$ & $2.35(1)$ & $0.009(1)$ & $2.39(1)$ & $0.005(3)$ & $2.39(3)$ & - \\
\hline 15YDC & $2.33(1)$ & $0.011(1)$ & 0.020 & $2.344(9)$ & $0.010(1)$ & 0.020 & $2.32(1)$ & $0.009(1)$ & $2.34(1)$ & $0.009(1)$ & $2.38(1)$ & $0.007(1)$ & $2.39(1)$ & $0.002(1)$ \\
\hline 20YDC & $2.32(1)$ & $0.011(2)$ & 0.020 & $2.332(9)$ & $0.011(1)$ & 0.020 & $2.31(1)$ & $0.011(1)$ & $2.32(1)$ & $0.010(1)$ & $2.38(1)$ & $0.004(1)$ & $2.37(1)$ & $0.004(1)$ \\
\hline 5SDC & $2.332(7)$ & $0.009(1)$ & 0.016 & $2.389(8)$ & $0.009(2)$ & 0.009 & $2.33(1)$ & $0.009(1)$ & $2.38(1)$ & $0.007(1)$ & $2.39(1)$ & $0.003(1)$ & $2.31(2)$ & - \\
\hline 10SDC & $2.34(1)$ & $0.009(1)$ & 0.020 & $2.379(9)$ & $0.011(2)$ & 0.009 & $2.33(1)$ & $0.010(1)$ & $2.37(1)$ & $0.009(1)$ & $2.40(1)$ & $0.006(2)$ & $2.35(2)$ & $0.002(1)$ \\
\hline 15SDC & $2.33(1)$ & $0.012(1)$ & 0.016 & $2.372(5)$ & $0.010(1)$ & 0.009 & $2.33(1)$ & $0.010(1)$ & $2.36(1)$ & $0.009(1)$ & $2.40(1)$ & $0.006(1)$ & $2.32(1)$ & $0.004(1)$ \\
\hline 20 SDC & $2.33(1)$ & $0.009(1)$ & 0.020 & $2.366(5)$ & $0.013(2)$ & 0.009 & $2.32(1)$ & $0.010(1)$ & $2.35(1)$ & $0.009(1)$ & $2.42(1)$ & $0.006(1)$ & $2.37(2)$ & $0.012(2)$ \\
\hline
\end{tabular}




\section{EXAFS second shell (2NN) conventional analysis and RMC results}

Table S3: Second shell distances $R$ and disorder factors $\sigma^{2}$ derived using conventional EXAFS (Artemis) analysis, and from RMC-EXAFS. The uncertainty of the last digit is given in parentheses.

\begin{tabular}{|c|c|c|c|c|c|c|c|c|c|}
\hline \multirow[t]{2}{*}{ Sample } & \multicolumn{4}{|c|}{ Conventional Analysis } & \multicolumn{5}{|c|}{ RMC-EXAFS } \\
\hline & $\begin{array}{c}\boldsymbol{R}^{C e-C e} \\
(\AA)\end{array}$ & $\begin{array}{c}\boldsymbol{\sigma}^{2} \\
\left(\AA^{2}\right)\end{array}$ & $\begin{array}{c}\boldsymbol{R}^{D o-C e} \\
(\AA))\end{array}$ & $\begin{array}{c}\boldsymbol{\sigma}^{2} \\
\left(\AA^{2}\right)\end{array}$ & $\begin{array}{c}\boldsymbol{R}^{C e-C e} \\
(\AA)\end{array}$ & $\begin{array}{c}\boldsymbol{\sigma}^{2} \\
\left(\AA^{2}\right)\end{array}$ & $\begin{array}{c}\boldsymbol{R}^{D \boldsymbol{D o}-\mathrm{Ce}} \\
(\AA \AA)\end{array}$ & $\begin{array}{c}\boldsymbol{\sigma}^{2} \\
\left(\AA^{2}\right)\end{array}$ & $\begin{array}{c}\boldsymbol{R}^{\boldsymbol{O}-\boldsymbol{O}} \\
(\AA)\end{array}$ \\
\hline $\mathrm{CeO}_{2}$ & ـ & - & - & - & $3.86(1)$ & $0.006(1)$ & - & - & 2.71 \\
\hline 5YDC & $3.854(7)$ & $0.007(1)$ & $3.82(3)$ & $0.009(3)$ & $3.86(1)$ & $0.005(1)$ & $3.84(1)$ & $0.009(1)$ & $2.72(1)$ \\
\hline 10YDC & $3.851(9)$ & $0.010(1)$ & $3.83(3)$ & $0.013(4)$ & $3.86(1)$ & $0.009(1)$ & $3.82(1)$ & $0.011(1)$ & 2.71(1) \\
\hline 15YDC & $3.85(1)$ & $0.010(1)$ & $3.83(2)$ & $0.015(3)$ & $3.86(1)$ & $0.008(1)$ & $3.83(1)$ & $0.013(1)$ & $2.71(1)$ \\
\hline 20YDC & $3.85(1)$ & $0.011(1)$ & $3.84(2)$ & $0.015(3)$ & $3.86(1)$ & $0.007(1)$ & $3.80(1)$ & $0.018(1)$ & $2.70(1)$ \\
\hline 5SDC & $3.855(8)$ & $0.008(1)$ & $3.83(9)$ & $0.01(1)$ & $3.87(1)$ & $0.008(1)$ & $3.78(1)$ & $0.010(1)$ & 2.71(1) \\
\hline 10SDC & $3.859(7)$ & $0.009(1)$ & $3.84(6)$ & $0.010(7)$ & $3.88(1)$ & $0.008(1)$ & $3.82(1)$ & $0.008(1)$ & $2.72(1)$ \\
\hline 15SDC & $3.843(7)$ & $0.008(1)$ & $3.81(5)$ & $0.012(6)$ & $3.88(1)$ & $0.007(1)$ & $3.84(1)$ & $0.011(1)$ & 2.73(1) \\
\hline 20SDC & $3.85(1)$ & $0.011(1)$ & $3.81(4)$ & $0.013(5)$ & $3.88(1)$ & $0.014(1)$ & $3.82(1)$ & $0.015(1)$ & $2.74(1)$ \\
\hline
\end{tabular}

\section{E. Procedure and Parameters for conventional EXAFS fitting}

For fitting the $1 \mathrm{NN}$ shell, data from the same edge (Ce, Sm, Y), collected on the same beamline (SSRL 2-2 or APS 5BMD) but with different films, were fit together, with shared $\mathrm{S}_{\mathrm{o}}{ }^{2}$ and $\Delta \mathrm{E}_{0}$. For a given Do edge, data collected on different beamlines shared the same $\Delta \mathrm{E}_{0}$. The coordination number of the $1 \mathrm{NN}$ shell was set to 7.5 for all edges. By doing this, the uncertainties of $\sigma_{\mathrm{Ce}-\mathrm{O}}^{2}$ and $\sigma_{\mathrm{Do}-\mathrm{O}}^{2}$ were reduced. After establishing fitting parameters for the $1 \mathrm{NN}$ (Ce-O and Do-O), the $1 \mathrm{NN}$ and $2 \mathrm{NN}$ shells were fit together. During this step, the parameters for the first shell were constrained to be the same as those obtained from the results of the $1 \mathrm{NN}$ shell fitting and parameters for the $2 \mathrm{NN}$ shell (Ce-Ce and Do-Ce) were extracted. Data from the same sample, collected at both Ce and Do edges, were fit together, with shared $R_{\mathrm{Ce} / \mathrm{Do}-\mathrm{O}}$ and $\sigma_{\mathrm{Ce} / \mathrm{Do}-\mathrm{O} \text {. }}^{2}$

Table S4: Parameters for Ce edge data reduction using conventional EXAFS (Artemis) analysis, namely, $k$-range and $R$-range. $k$-weight used for all data is 3 .

\begin{tabular}{|c|c|c|c|c|c|c|c|c|c|}
\hline \multirow[t]{2}{*}{ Sample } & \multirow[t]{2}{*}{ Beamline } & \multicolumn{4}{|l|}{ First shell } & \multicolumn{4}{|c|}{ Second Shell } \\
\hline & & $k_{\min }\left(\AA^{-1}\right)$ & $\boldsymbol{k}_{\max }\left(\AA^{-1}\right)$ & $\boldsymbol{R}_{\min }(\AA)$ & $\boldsymbol{R}_{\max }(\AA)$ & $\boldsymbol{k}_{\min }\left(\AA^{-1}\right)$ & $\boldsymbol{k}_{\max }\left(\AA^{-1}\right)$ & $\boldsymbol{R}_{\min }(\AA)$ & $\boldsymbol{R}_{\max }(\AA)$ \\
\hline 5YDC & SSRL 2-2 & 3 & 10 & 1.35 & 2.30 & 3 & 10 & 2 & 4.5 \\
\hline 10YDC & APS 5BMD & 3 & 10 & 1.35 & 2.39 & 2 & 10 & 2 & 4.5 \\
\hline $15 Y D C$ & SSRL 2-2 & 3 & 10 & 1.35 & 2.30 & 2 & 10 & 2 & 4.5 \\
\hline 20YDC & SSRL 2-2 & 3 & 10 & 1.35 & 2.30 & 3 & 10 & 2 & 4.5 \\
\hline 5SDC & APS 5BMD & 3 & 10 & 1.35 & 2.39 & 3 & 10 & 2 & 4.5 \\
\hline 10SDC & SSRL 2-2 & 3 & 10 & 1.35 & 2.30 & 3 & 10 & 2 & 4.5 \\
\hline 15SDC & APS 5BMD & 3 & 10 & 1.35 & 2.36 & 2 & 10 & 2 & 4.5 \\
\hline 20SDC & SSRL 2-2 & 3 & 10 & 1.35 & 2.30 & 3 & 10.5 & 2 & 4.5 \\
\hline
\end{tabular}


Table S5: Parameters for Do edge data reduction using conventional EXAFS (Artemis) analysis, namely, $k$-range and $R$-range. $k$-weight used for all data is 3 .

\begin{tabular}{|c|c|c|c|c|c|c|c|c|c|}
\hline \multirow[t]{2}{*}{ Sample } & \multirow[t]{2}{*}{ Beamline } & \multicolumn{4}{|c|}{ First shell } & \multicolumn{4}{|c|}{ Second Shell } \\
\hline & & $\begin{array}{c}k_{\min } \\
\left(\AA^{-1}\right)\end{array}$ & $\begin{array}{l}\boldsymbol{k}_{\max } \\
\left(\AA^{-1}\right)\end{array}$ & $\begin{array}{c}\boldsymbol{R}_{\min } \\
(\AA)\end{array}$ & $\begin{array}{c}\boldsymbol{R}_{\max } \\
(\AA)\end{array}$ & $\begin{array}{c}\boldsymbol{k}_{\min } \\
\left(\AA^{-1}\right)\end{array}$ & $\begin{array}{l}k_{\max } \\
\left(\AA^{-1}\right)\end{array}$ & $\begin{array}{c}\boldsymbol{R}_{\min } \\
(\AA)\end{array}$ & $\begin{array}{c}\boldsymbol{R}_{\max } \\
(\AA)\end{array}$ \\
\hline 5YDC & SSRL 2-2 & 3.53 & 10 & 1.35 & 2.39 & 3 & 12.5 & 2 & 4 \\
\hline 10YDC & APS 5BMD & 3.53 & 10.5 & 1.35 & 2.38 & 3 & 11 & 2 & 4.2 \\
\hline $15 \mathrm{YDC}$ & SSRL 2-2 & 3.53 & 10 & 1.35 & 2.41 & 2 & 10 & 2 & 4.2 \\
\hline 20YDC & SSRL 2-2 & 3.53 & 10 & 1.32 & 2.47 & 3 & 10.5 & 2 & 4.5 \\
\hline 5SDC & APS 5BMD & 3 & 9.5 & 1.65 & 2.66 & 3.5 & 10 & 2 & 4.5 \\
\hline 10SDC & SSRL 2-2 & 2 & 9.5 & 1.65 & 2.5 & 3.5 & 10.5 & 2 & 4.7 \\
\hline 15SDC & APS 5BMD & 3 & 9.5 & 1.65 & 2.71 & 3.5 & 9.8 & 2 & 5 \\
\hline 20SDC & SSRL 2-2 & 2 & 9.5 & 1.65 & 2.5 & 3.5 & 9.5 & 2 & 4.5 \\
\hline
\end{tabular}

\section{F. Conventional EXAFS fitting results}
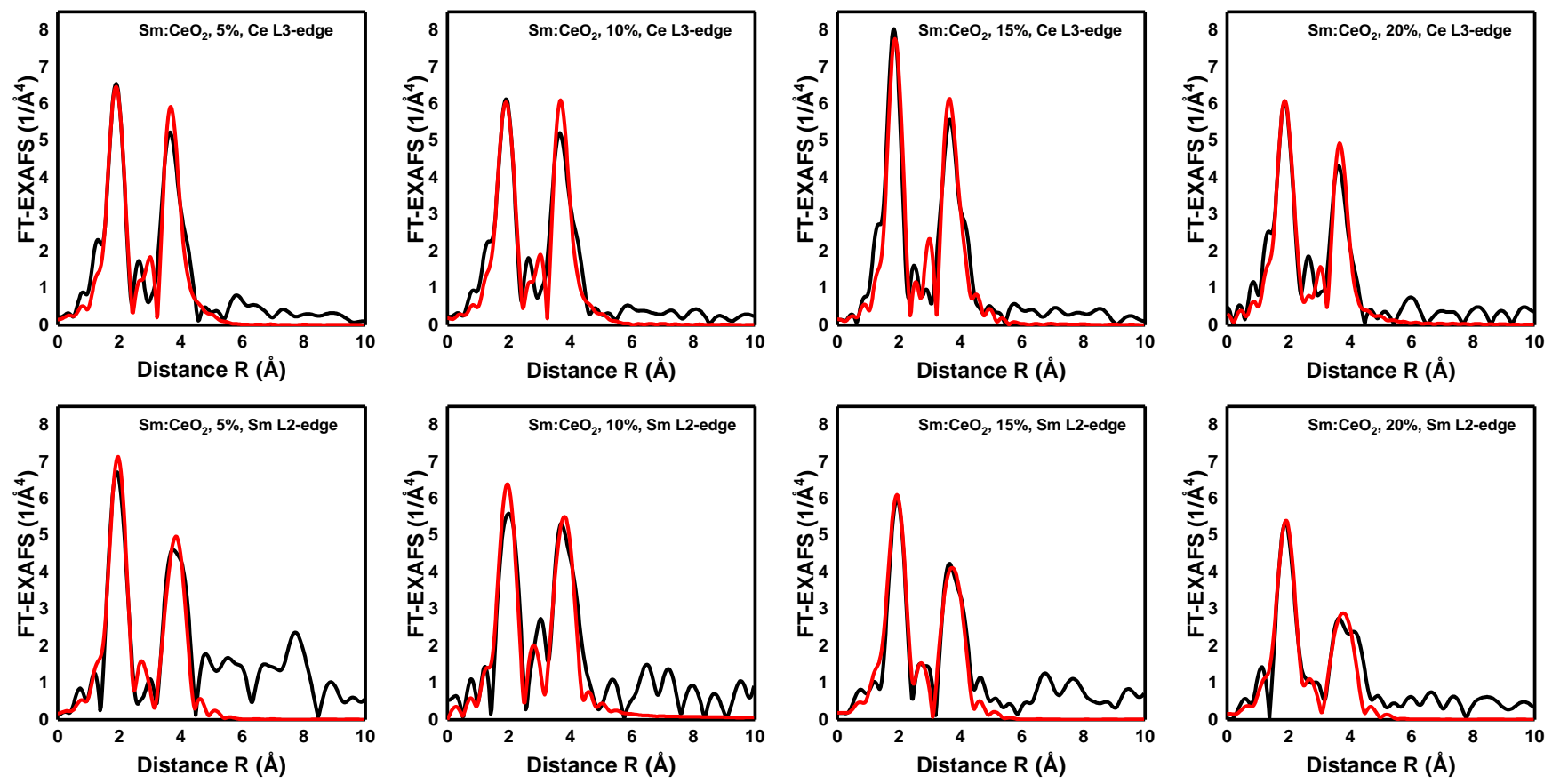

Figure S2: Agreement between experimental (Black) and theoretical (Red) spectra in R-space, for Ce $\mathrm{L}_{3}$-edge and $\mathrm{Sm}$ $\mathrm{L}_{2}$-edge data, obtained with conventional EXAFS fits of Sm doped ceria thin films. 

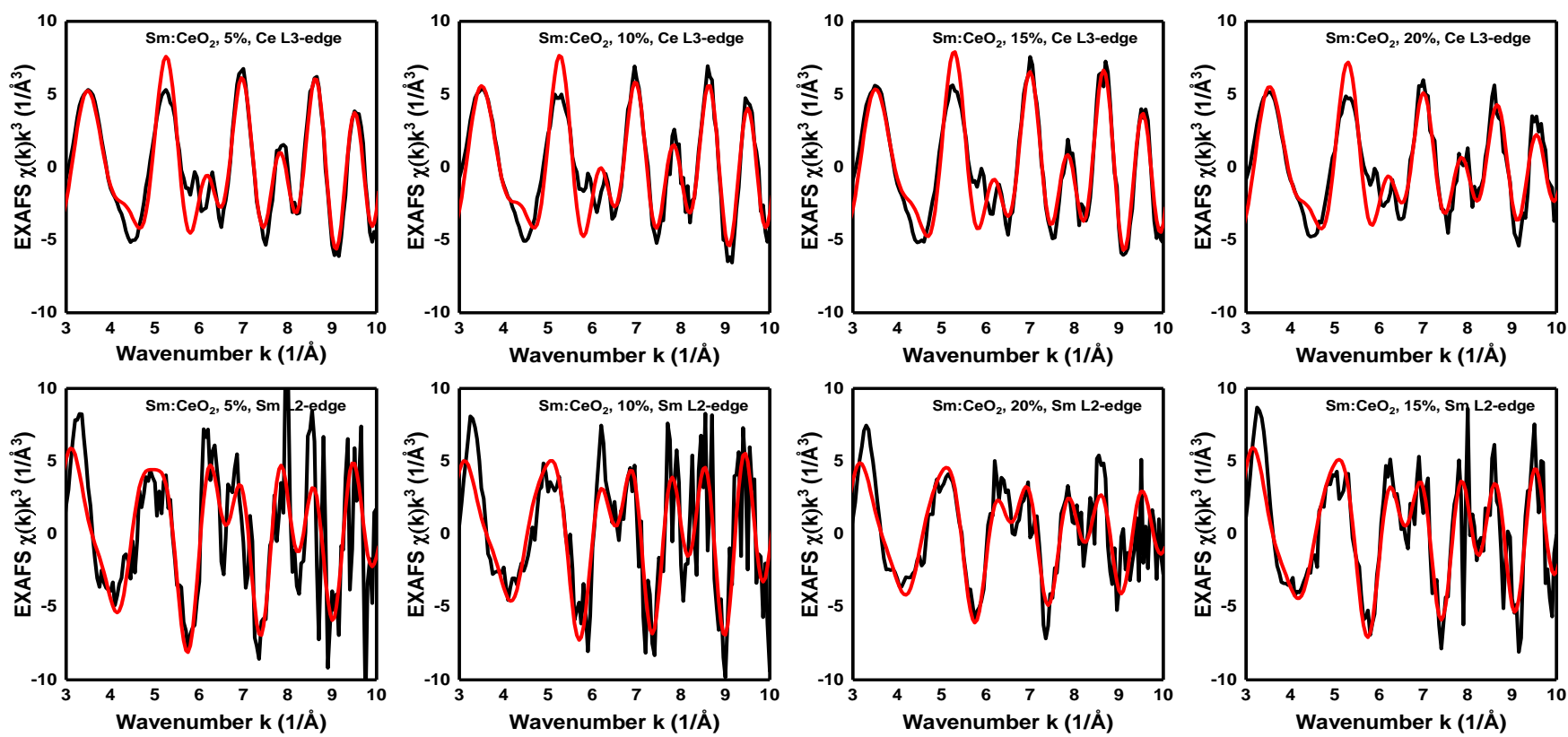

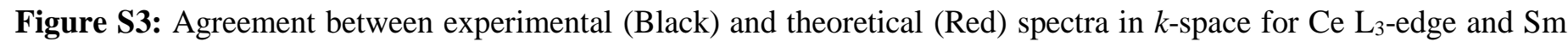
$\mathrm{L}_{2}$-edge data, obtained in conventional EXAFS fits of Sm doped ceria thin films.
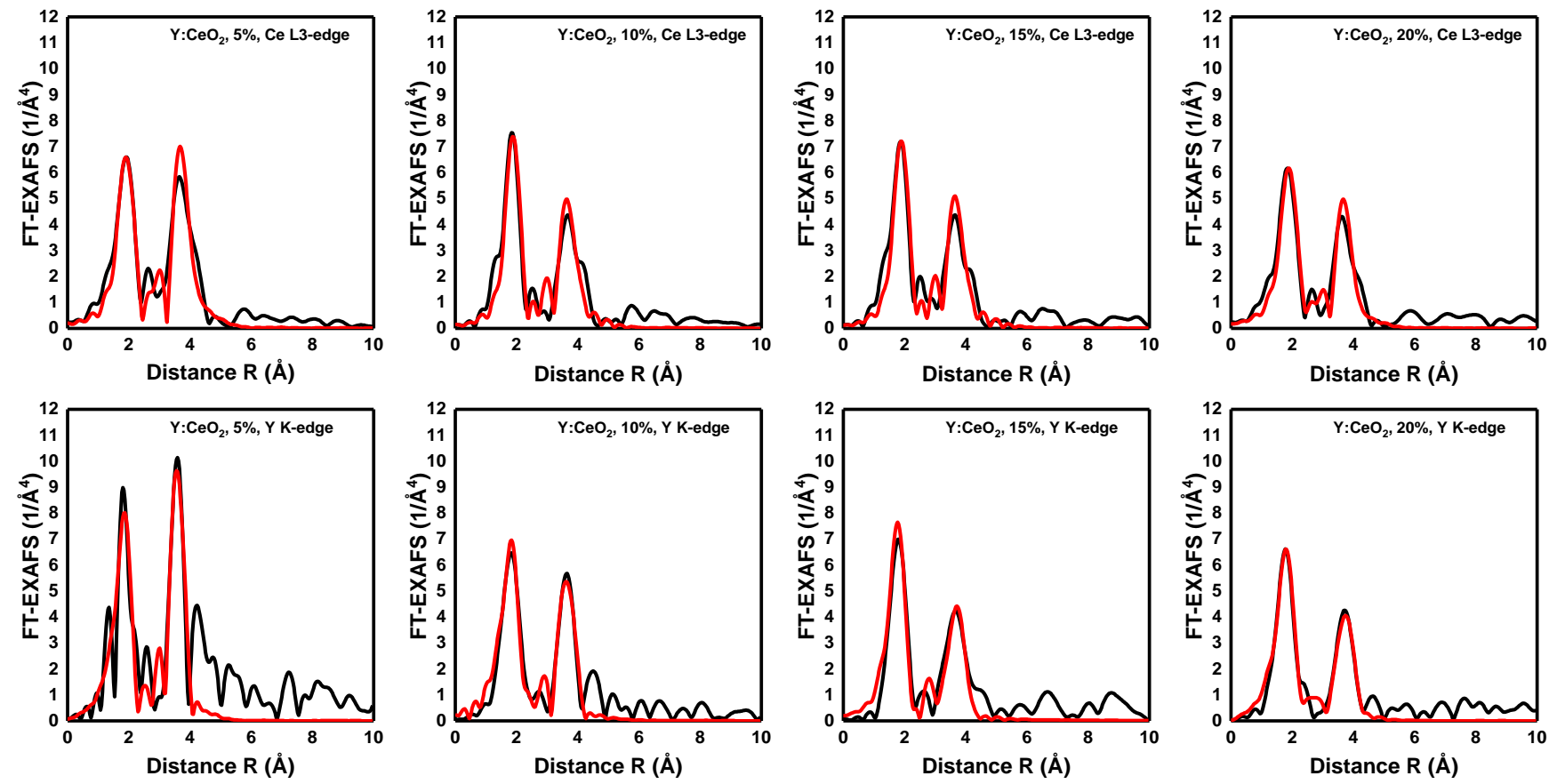

Figure S4: Agreement between experimental (Black) and conventional EXAFS fitting spectra (Red) in R-space, for Ce $\mathrm{L}_{3}$-edge and $\mathrm{Y} \mathrm{K}$-edge data, obtained in conventional EXAFS fits of $\mathrm{Y}$ doped ceria thin films. 

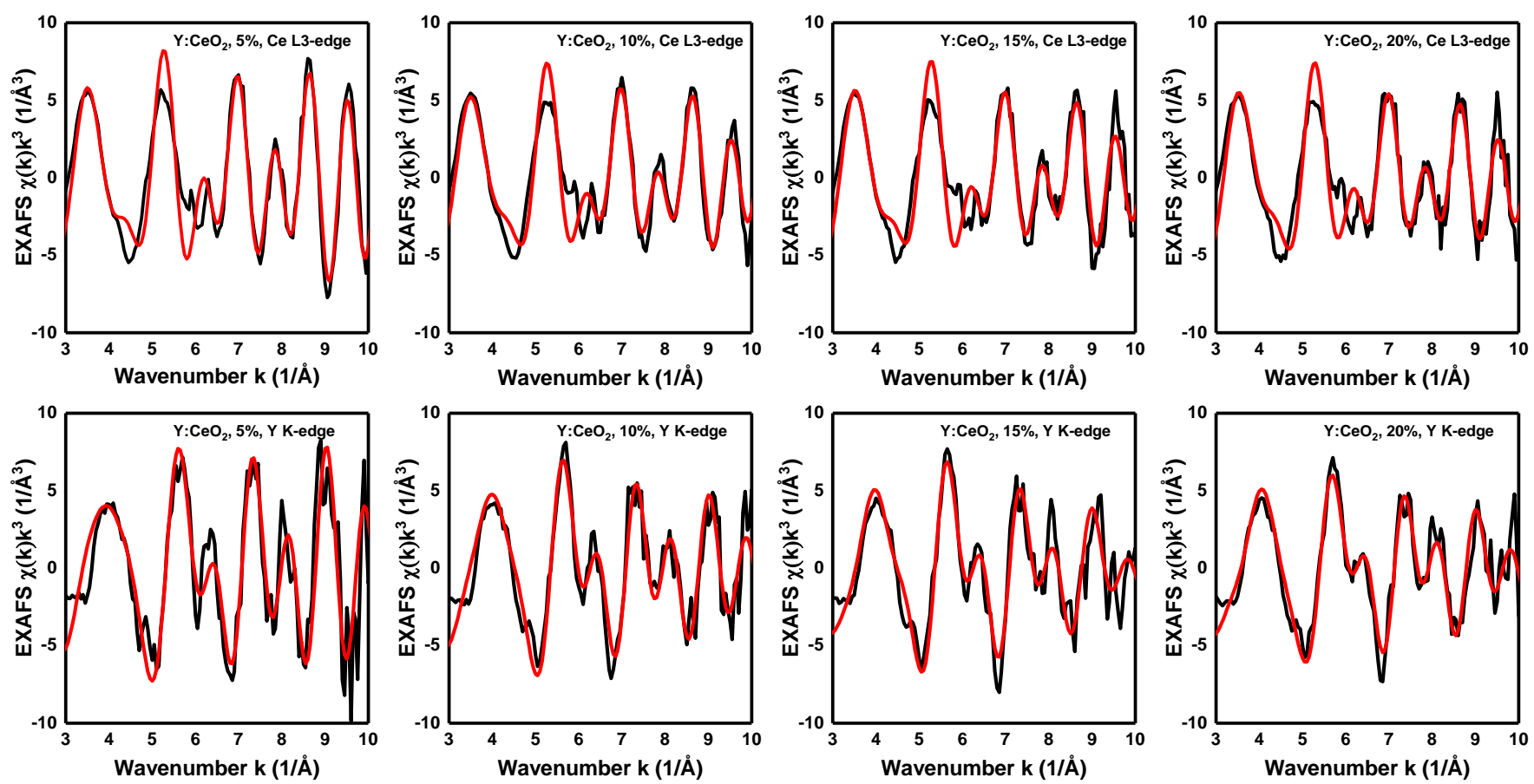

Figure S5: Agreement between experimental (Black) and theoretical (Red) spectra in k-space for Ce $\mathrm{L}_{3}$-edge and Y Kedge data, obtained in conventional EXAFS fits of Y doped ceria thin films.

\section{G. Agreement between theoretical RMC-EXAFS and experimental data}

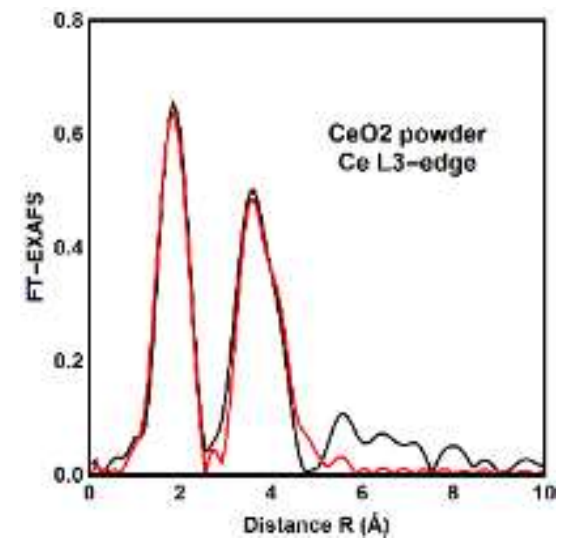

Figure S6: Agreement between experimental (Black) and theoretical (Red) spectra for $\mathrm{Ce}_{3}$-edge obtained in RMCEXAFS fits for pure $\mathrm{CeO}_{2}$ in powder form (EXAFS data from Clark et al. ref [54] in the main text). 

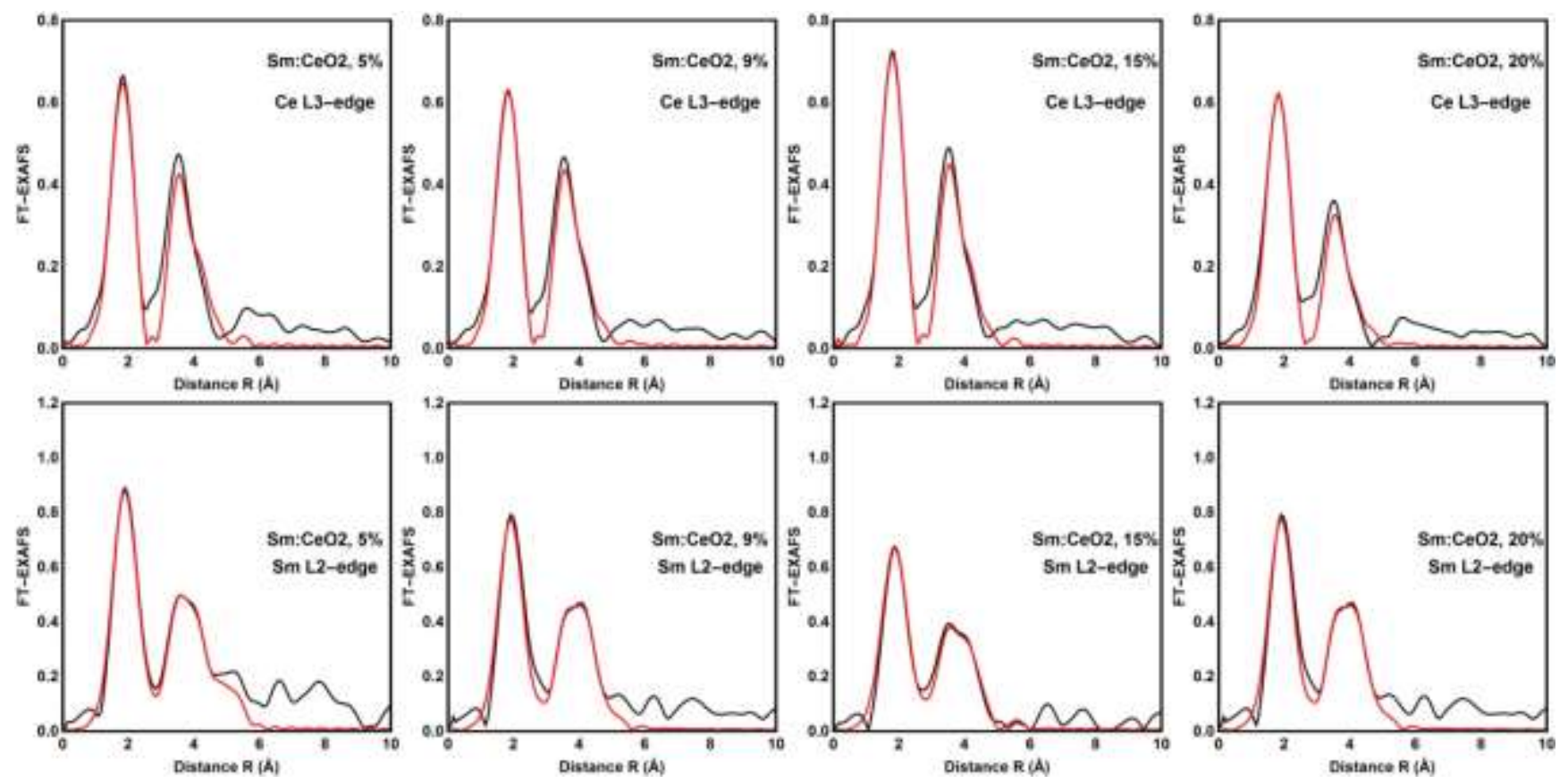

Figure S7: Agreement between experimental (Black) and theoretical (Red) spectra for $\mathrm{Ce}_{3}$-edge and $\mathrm{Sm} \mathrm{L}_{2}$-edge data, obtained in RMC-EXAFS fits of Sm doped ceria thin films. $\mathrm{R}$ factors for all fits are $\sim 0.04$.
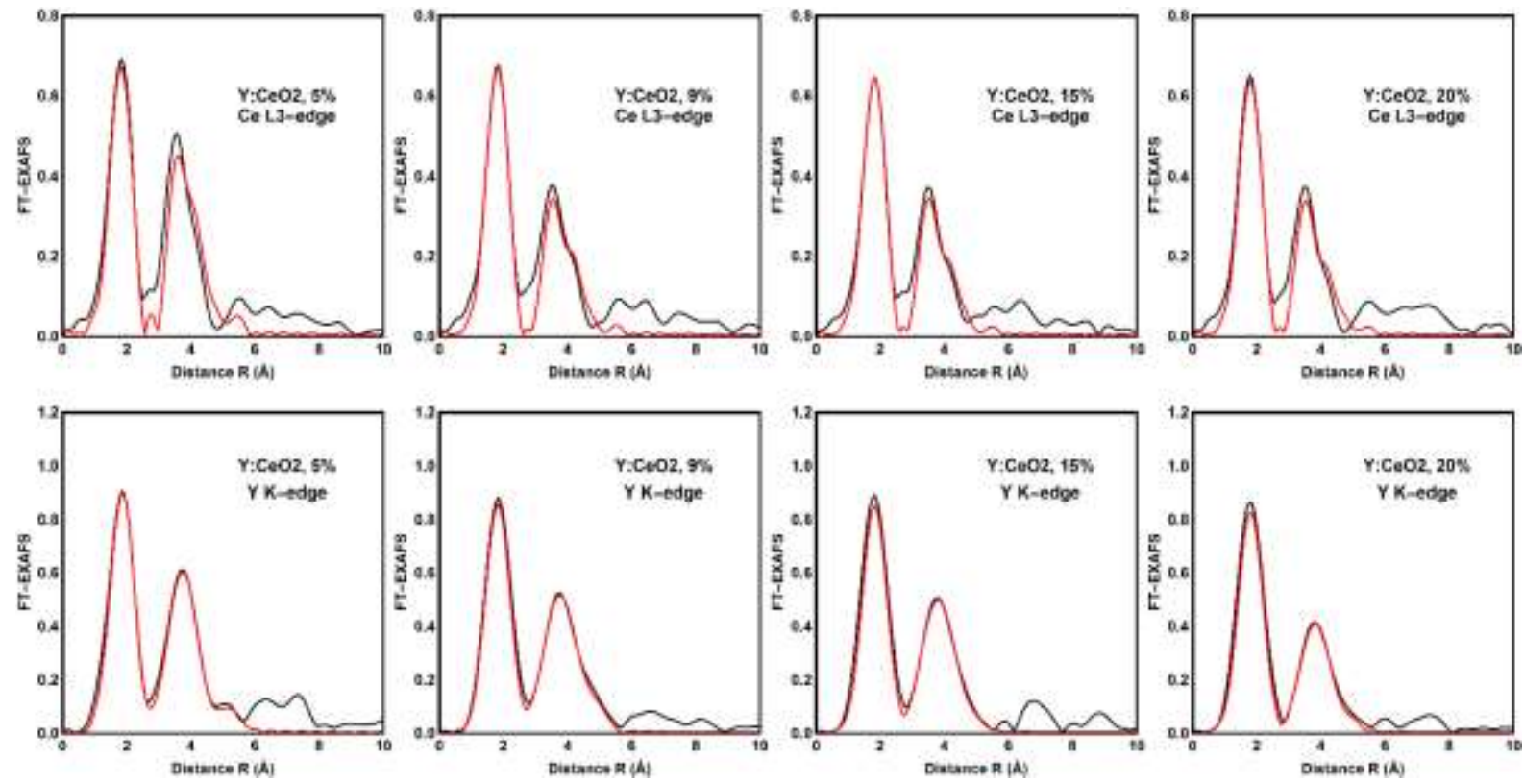

Figure S8: Agreement between experimental (Black) and theoretical (Red) spectra for $\mathrm{Ce}_{2}$-edge and Y K-edge data, obtained in RMC-EXAFS fits of Y doped ceria thin films. R factors for all fits are $~ 0.04$. 


\section{H. Effect of double excitation or $\mathrm{Ce}^{3+}$ impurities on structural parameters derived from RMC-EXAFS simulations}

According to a paper by Fonda et al. (ref [56] in the main text) analysis of EXAFS data from $\mathrm{CeO}_{2}$ can be complicated by two different possible effects:

1) A double-excitation feature at $c a .5854 .2 \mathrm{eV}$, which can be approximated by a Lorentzian function.

2) The mixed-valence behavior of $\mathrm{Ce}$, which can be approximated by adding two EXAFS signals, which differ only in their $k$-scale origin and in the relative weight of the signal amplitude.

In Figure $\mathrm{S} 9$-a below we compare the experimental $\mathrm{CeO}_{2}$ spectrum to the $\mathrm{RMC}$ generated spectrum. While the overall agreement between RMC spectra and experiment is good, there are two regions, where larger differences can be observed: around $k=3-4$ and $6 \AA^{-1}$. The latter can be explained by the presence of the abovementioned Lorentzian-like double excitation feature, while the former one - by mixed valence behavior of Ce.

In order to demonstrate that feature " 1 " (around $k=6 \AA^{-1}$ ) indeed is the result of a double-excitation feature, we have added a Lorentzian function to the RMC spectrum (in $E$-space), and optimized the parameters of Lorentzian function for optimal agreement with experiment (see Figure S9-b below). The position, width and intensity of the Lorentzian feature are similar to those in the paper by Fonda et al.

To demonstrate the impact of the mixed valence effect on the data, we have also followed the recipe by Fonda et al. and constructed a new spectrum from the original RMC result, using the following equation:

$\chi_{\text {new }}(E)=\alpha \chi_{R M C}(E)+(1-\alpha) \chi_{R M C}(E+\delta)$,

where $\alpha=0.66$ and $\delta=7 \mathrm{eV}$.

This modified spectrum is compared with the original one in Figure S9-c below. As one can see, such distortion indeed significantly affects the EXAFS amplitude in the problematic region between ca. 3 and $4 \AA^{-1}$. 

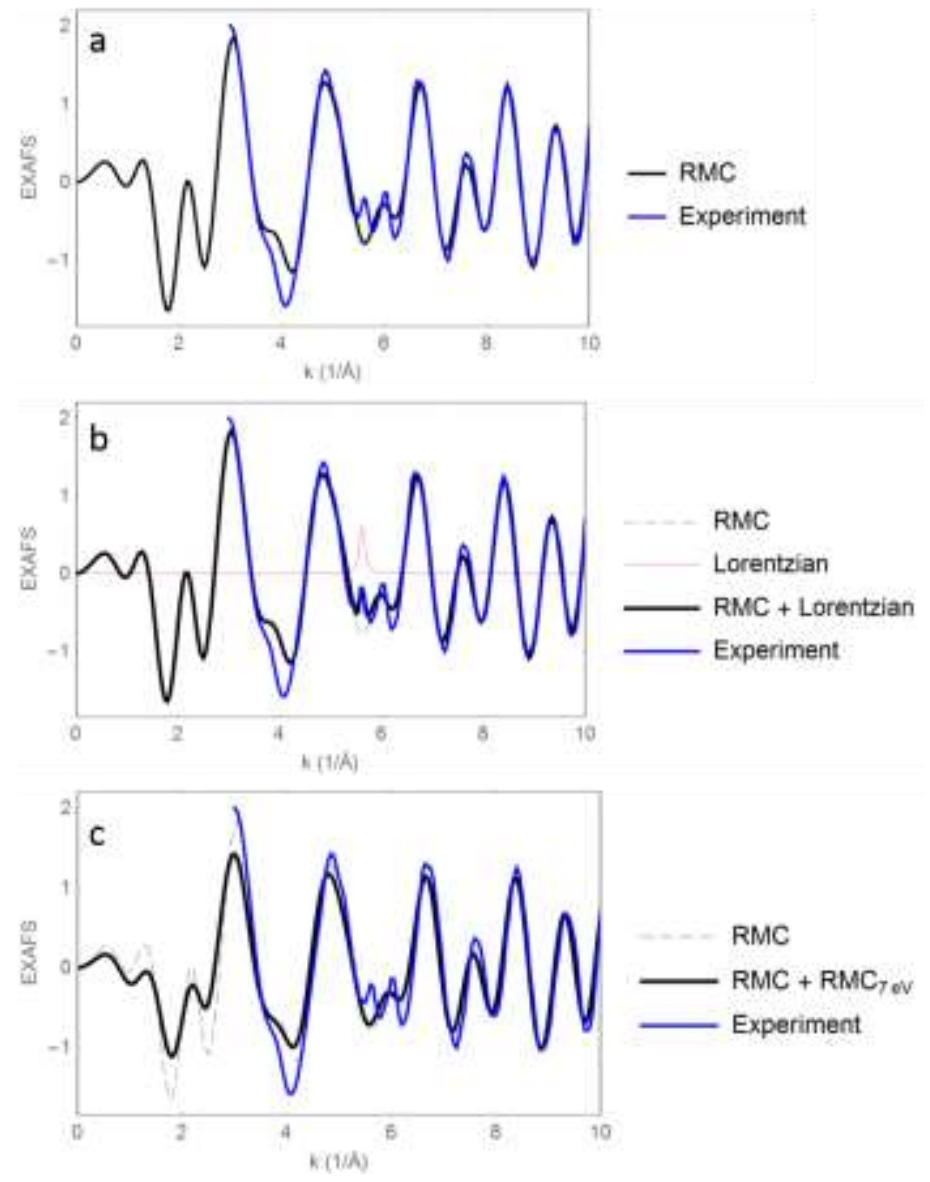

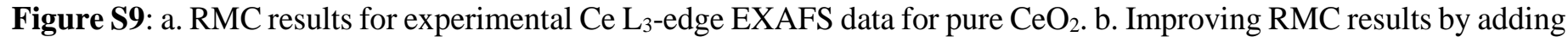
a Lorentzian-like function to the modelled double-excitation feature. c. Modeling of the influence of the EXAFS artifact due to mixed-valence behavior of $\mathrm{Ce}$.

In order to verify if any of these artifacts can affect the values of structural parameters extracted from RMC simulations, we have generated a model EXAFS spectrum for $\mathrm{CeO}_{2}$ : the spectrum was calculated for an ideal $\mathrm{CeO}_{2}$ lattice, where all atoms were randomly displaced by no more than $0.1 \AA$. The model spectrum, where, for simplicity, we considered singlescattering paths only, is shown in Figure S10-a below (Model). Next, we have introduced two different distortions: (i) An additional Lorentzian feature (Figure S10-a) and (ii) simulation of the mixed valence effect according to the equation above (Figure S10-b). 

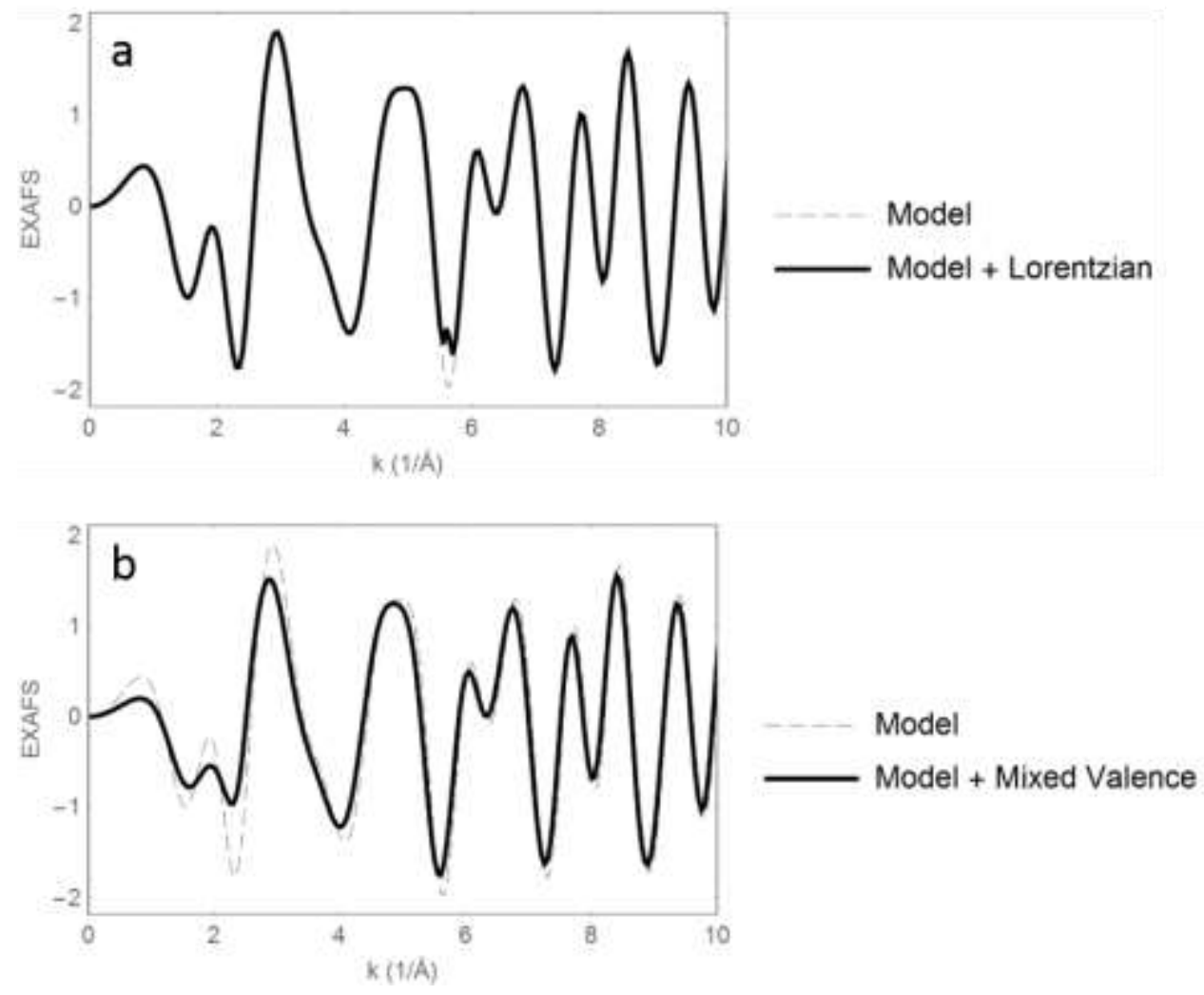

Figure S10: a. Model data and distorted model data (Lorentzian-type distortion) b. Model data and distorted model data (mixed valence-type distortion).

We then performed RMC simulations, where we have tried to reconstruct the underlying structure for the non-distorted and the two distorted spectra. In Table S6 we summarized the averaged $\mathrm{Ce}-\mathrm{O}$ distance and disorder factor, obtained from such RMC simulations, and compared it with the true value for this structure model. As one can see, neither of the effects investigated results in significant changes in the structure parameters - the changes in interatomic distances and disorder factors are within the uncertainty of our analysis.

Table S6: Influence of artifacts in EXAFS spectra on $\mathrm{Ce}-\mathrm{O}$ bond length and disorder factor, extracted from RMC simulations

\begin{tabular}{|l|l|l|l|l|}
\hline Parameters & $\begin{array}{l}\text { True } \\
\text { value }\end{array}$ & $\begin{array}{l}\text { RMC result for } \\
\text { original } \\
\text { spectrum }\end{array}$ & $\begin{array}{l}\text { RMC result for } \\
\text { distorted } \\
\text { spectrum } \\
\text { (Lorentzian } \\
\text { distortion) }\end{array}$ & $\begin{array}{l}\text { RMC result for } \\
\text { distorted } \\
\text { spectrum } \\
\text { (Mixed-valence } \\
\text { distortion) }\end{array}$ \\
\hline Ce-O distance $(\mathbf{A})$ & 2.350 & 2.350 & 2.349 & 2.358 \\
\hline $\boldsymbol{\sigma}^{\mathbf{2}}\left(\tilde{\mathbf{A}}^{\mathbf{2})}\right.$ & 0.0038 & 0.0042 & 0.0040 & 0.0052 \\
\hline
\end{tabular}




\section{Considering anisotropy of lattice parameters}

To test the sensitivity of the interatomic distances acquired by RMC-EXAFS to the anisotropy in lattice parameter, we perform simulations for 15SDC film both with cubic structure model, as well as non-cubic (anisotropic) model. The lattice constants for the two models are given as follows:

\section{Table S7}

\begin{tabular}{|c|c|c|c|}
\hline Parameter & $\mathbf{a}(\stackrel{\AA}{)})$ & $\mathbf{b}(\stackrel{\AA}{\mathbf{A}})$ & $\mathbf{c}(\stackrel{\AA}{\mathbf{A}})$ \\
\hline cubic & 5.450 & 5.450 & 5.450 \\
\hline Non-cubic & 5.430 & 5.430 & 5.480 \\
\hline
\end{tabular}

The spectra, obtained from RMC simulations for these two cases, are compared in Figure S11. In both cases relatively good agreement with experimental data was obtained. Bond length distribution functions, obtained in both cases, are compared in Figure S12. The obtained values of structure parameters are compared in Table S8. The two different structure models (cubic and non-cubic) yield similar results, for both RDF shapes and bond length values (with the exception of values for Do-Vo, which are not considered in the current work), demonstrating that small differences in the lattice parameter values in orthogonal directions do not influence the outcome of the parameters discussed in this work.
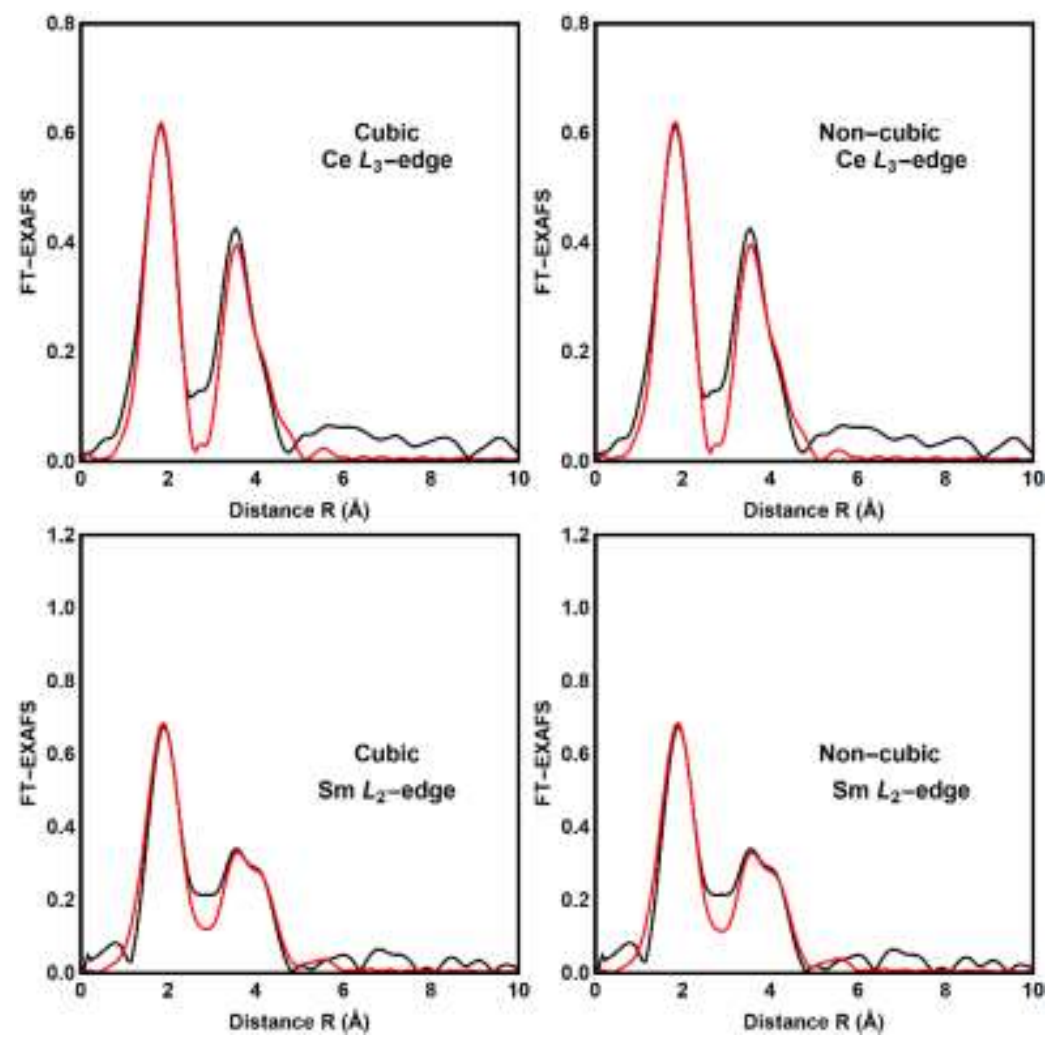

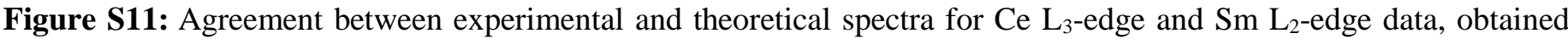
with RMC-EXAFS fits of $15 \mathrm{~mol} \% \mathrm{Sm}$ dope ceria for different model structures, cubic and non-cubic (anisotropic). 

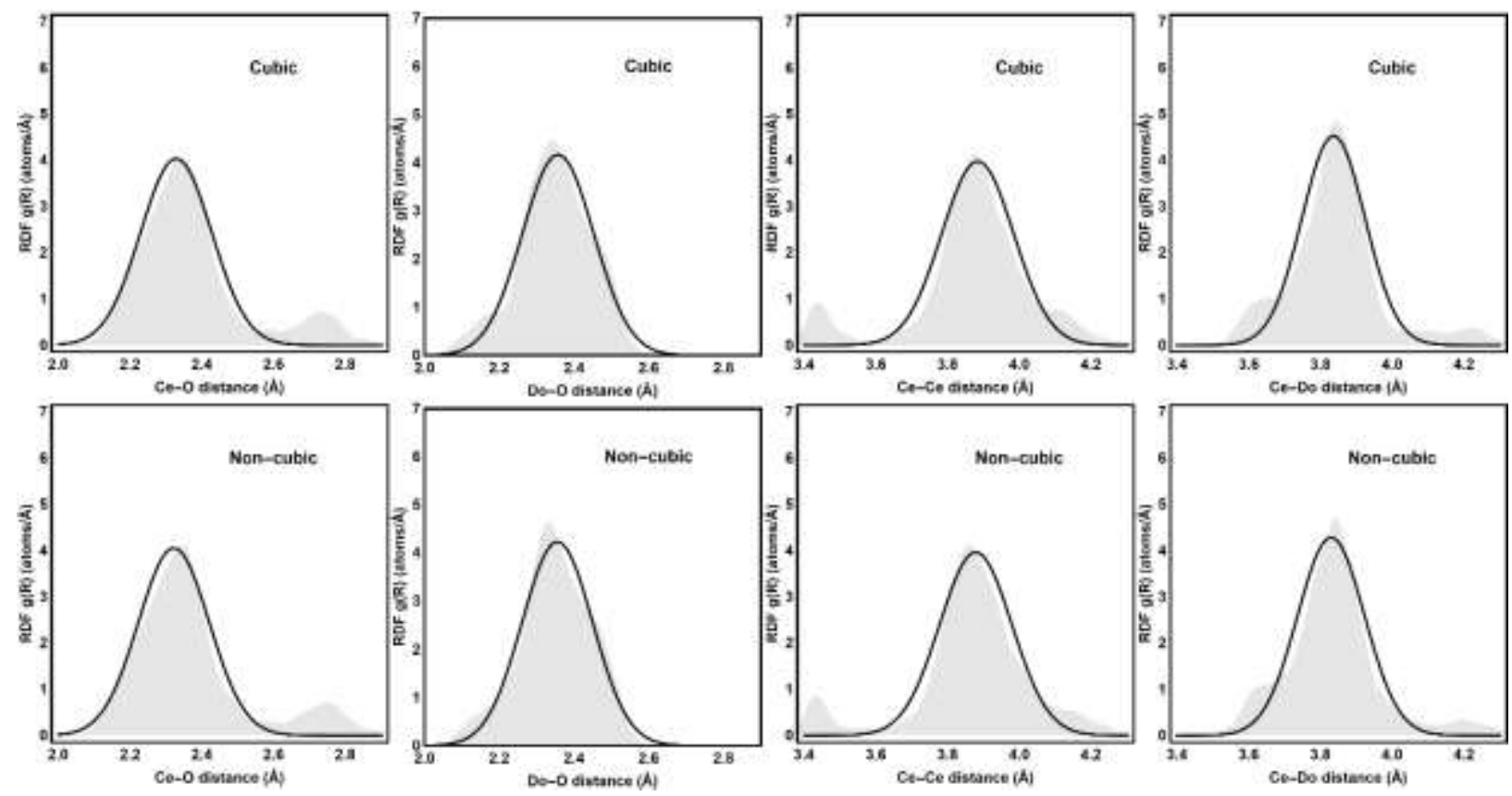

Figure S12: RDF functions for Ce-O, Sm-O, Ce-Ce, Ce-Sm, Sm-V and Ce-V inter atomic distances, obtained with RMC for $15 \mathrm{~mol} \% \mathrm{Sm}$ dope ceria and with different model structures.

Table S8: Results of RMC-EXAFS analysis for a $15 \mathrm{~mol} \% \mathrm{Sm}$ dope ceria film for cubic and non-cubic models.

\begin{tabular}{|c|c|c|c|c|c|c|}
\hline \multirow{2}{*}{ Parameter } & \multicolumn{3}{|c|}{ Cubic model } & \multicolumn{3}{|c|}{ Non-cubic model } \\
\hline & XRD & $\begin{array}{l}\text { Conv. } \\
\text { Analysis }\end{array}$ & RMC-EXAFS & XRD & $\begin{array}{l}\text { Conv. } \\
\text { analysis }\end{array}$ & RMC-EXAFS \\
\hline $\mathbf{R}(\mathrm{Ce}-\mathrm{O}), \AA$ & 2.360 & $2.33(1)$ & 2.33 & 2.359 & $2.33(1)$ & 2.32 \\
\hline$\sigma^{2}(\mathrm{Ce}-\mathrm{O}), \AA^{2}$ & - & $0.011(1)$ & 0.010 & - & $0.011(1)$ & 0.010 \\
\hline R(Do-O), Å & 2.360 & $2.372(6)$ & 2.36 & 2.359 & $2.372(6)$ & 2.36 \\
\hline$\sigma^{2}(\mathrm{Do}-\mathrm{O}), \AA^{2}$ & - & $0.010(1)$ & 0.009 & - & $0.010(1)$ & 0.009 \\
\hline $\mathbf{R}(\mathrm{Ce}-\mathrm{Ce}), \AA$ & 3.854 & $3.861(8)$ & 3.88 & 3.851 & $3.861(8)$ & 3.88 \\
\hline$\sigma^{2}(\mathrm{Ce}-\mathrm{Ce}) \AA^{2}$ & - & $0.010(1)$ & 0.010 & - & $0.010(1)$ & 0.010 \\
\hline R(Do-Ce), Å & 3.854 & $3.83(4)$ & 3.84 & 3.851 & $3.83(4)$ & 3.83 \\
\hline$\sigma^{2}(\mathrm{Do}-\mathrm{Ce}) \AA^{2}$ & - & $0.011(5)$ & 0.008 & - & $0.011(5)$ & 0.009 \\
\hline $\mathbf{R}(\mathrm{Ce}-\mathrm{V}), \AA$ & - & - & 2.40 & - & - & 2.41 \\
\hline$\sigma^{2}(\mathrm{Ce}-\mathrm{V}), \AA^{2}$ & - & - & 0.006 & - & - & 0.006 \\
\hline $\mathbf{R}(\mathbf{D o}-\mathrm{V}), \AA$ & - & - & 2.32 & - & - & 2.34 \\
\hline$\sigma^{2}(\mathrm{Do}-\mathrm{V}), \AA^{2}$ & - & - & 0.004 & - & - & 0.003 \\
\hline
\end{tabular}




\section{J. Estimating the required $\mathrm{R}\left(\mathrm{Ce}-\mathrm{Vo}_{0}\right)$ to compensate for the XRD-EXAFS mismatch}

First shell cation distance is obtained from XRD using:

$$
R_{X R D}^{\text {cat-o }}=\frac{\sqrt{3}}{4} \cdot a_{\text {average }}
$$

Since EXAFS is element specific, we obtain $R_{E X A F S}^{c a t-O}$ by weighting the first shell distance aroud the Ce and the dopant cations as follows:

$$
R_{E X A F S}^{c a t-O}=R_{E X A F S}^{C e-O} \cdot(1-x)+R_{E X A F S}^{D o-O} \cdot x
$$

Next, we incorporate $R_{E s t i m a t e d}^{c a t-V_{O}}$ distance (which includes contributions from both $R^{C e-V_{o}}$ and $R^{D o-V_{O}}$ ) with the weighted average of first shell distances $R_{E X A F S}^{c a t-O}$ (eq.(2), by considering doped ceria stoichiometry: $\mathrm{Ce}_{1-x} D o_{x} \mathrm{O}_{2-\frac{x}{2}}$. The fraction of vacancies out of total oxygen sites is $\left(\frac{x}{2}\right) / 2=\frac{x}{4}$, and the combined term (right hand side in eq.3) is compared to the expected $R_{X R D}^{c a t-O}$ from (eq.1).

$$
R_{X R D}^{c a t-O}=\left(1-\frac{x}{4}\right) \cdot R_{E X A F S}^{c a t-O}+\frac{x}{4} \cdot R_{E s t i m a t e d}^{c a t-V_{O}}
$$

The magnitude of $R_{E s t i m a t e d}^{\text {Cat } V_{o}}$ required to balance between $R_{E X A F S}^{\text {cat-O }}$ and $R_{X R D}^{\text {cat-O }}$ is extracted as follows:

$$
R_{E s t i m a t e d}^{\text {cat }-V_{O}}=\frac{4}{x}\left[R_{X R D}^{\text {cat-O }}-R_{E X A F S}^{\text {cat-O }}\left(1-\frac{x}{4}\right)\right]
$$

In Figure S13, the $R_{\text {Estimated }}^{\text {cat } V_{o}}$ distance for a Sm doped film, is compared to Sm first and second shell distances extracted from the RMC-EXAFS model (Table S2 and Table S3). We can see that the $R_{\text {Estimated }}^{\text {cat } V_{o}}$ estimated using a weighted average are unreasonably large, approaching the second shell distance for lower concentrations of Sm and being expanded by $\sim 30 \%$ compared to the first shell distance $R^{C e-O}$. On the other hand, $R_{E X A F S}^{C e-V_{o}}$ and $R_{E X A F S}^{S m-V_{o}}$ extracted from the simulation are closer to the other first shell distances. The fact that a weighted average of the first shell EXAFS data cannot be used to obtain the average cat-O distances observed by XRD, emphasizes that the lattice has locally lost its fluorite structure upon doping. 


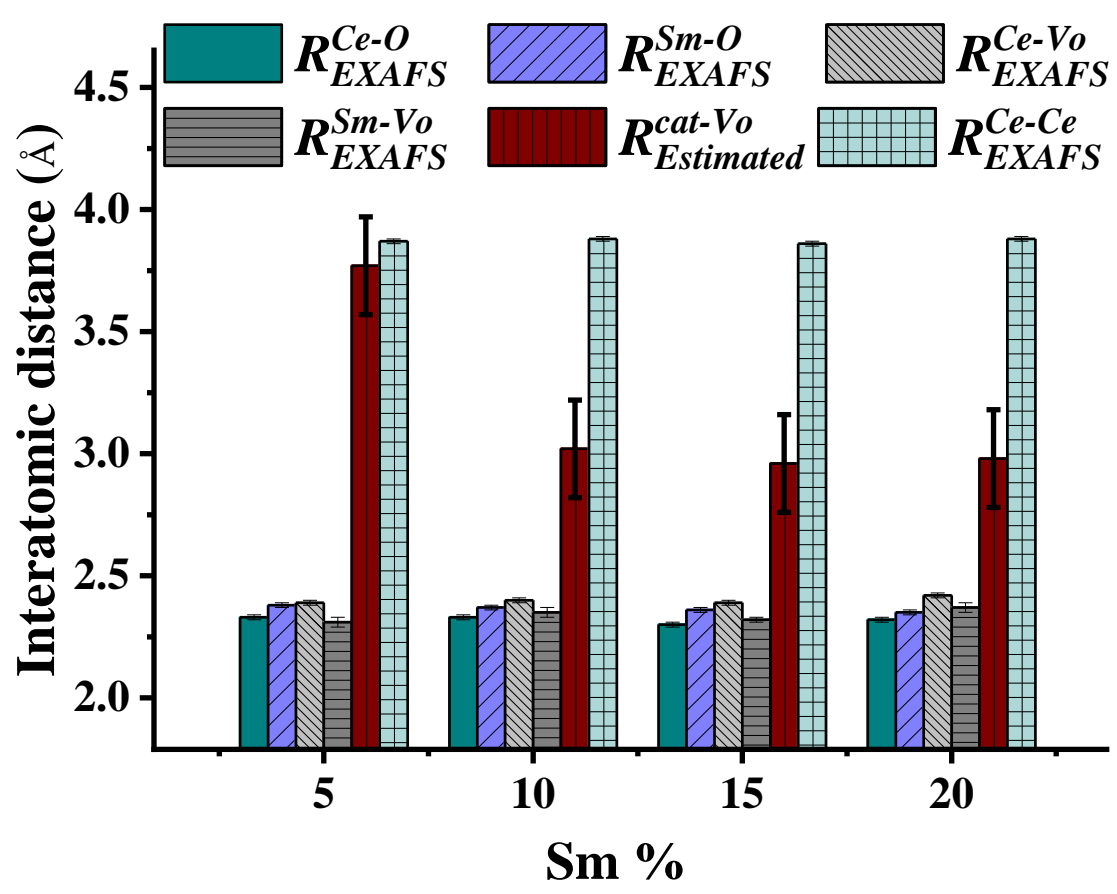

Figure S13: Estimated Cat-Vo distances $R_{\text {Estimated }}^{\text {cat-Vo }}$ obtained by comparing a weighted average of the RMC-EXAFSderived first shell $(1 \mathrm{NN})$ distances $R_{E X A F S}^{C e-O}, R_{E X A F S}^{D o-O}$ and $R_{E s t i m a t e d}^{c a t-V o}$, to the average XRD first shell distance $R_{X R D}^{c a t-O}$ (assuming a fluorite structure). The resulting $R_{\text {Estimated }}^{\text {Cat-Vo }}$ value is compared to distances extracted from RMC-EXAFS $R_{E X A F S}^{C e-V o}$, and $R_{E X A F S}^{S m-V o}$ and to the Ce second shell (2NN) distance obtained by RMC-EXAFS $R_{E X A F S}^{C e-C e}$ to emphasize that the result for $R_{\text {Estimated }}^{\text {cat-Vo }}$ is unreasonably large.

\section{K. Fitting interatomic distance distributions from RMC}

In the figures below: a. Distributions of the first coordination shell distances $R_{E X A F S}^{C e-O}$ for the control $\mathrm{CeO}_{2}$ pure material, as obtained by RMC-EXAFS (EXAFS data from Clark et al. ref [54] in the main text). b-e. Distributions for Sm doped ceria samples with dopant concentration from 5 to 20mol\%. "Fixed Gaussian 1" and "Fixed Gaussian 2" are kept constant. "Varied Gaussian" represents the fit for the high- $R$ artefact which lies outside the physically significant data range, both in signal intensity and in inter-atomic distance. Small peaks in RDFs corresponding to $R$ values beyond $2.6 \AA$ are artifacts of the RMC procedure (since they can be detected even for pure $\mathrm{CeO}_{2}$ ) and are the result of the finite number of RMC iterations, low statistics, and relative insensitivity of the EXAFS signal to these RDF regions. Ambiguities in the determination of non-structural parameters (energy reference point $E_{0}$ and amplitude reduction factors $S_{0}{ }^{2}$ ) can additionally contribute to these artefacts. 

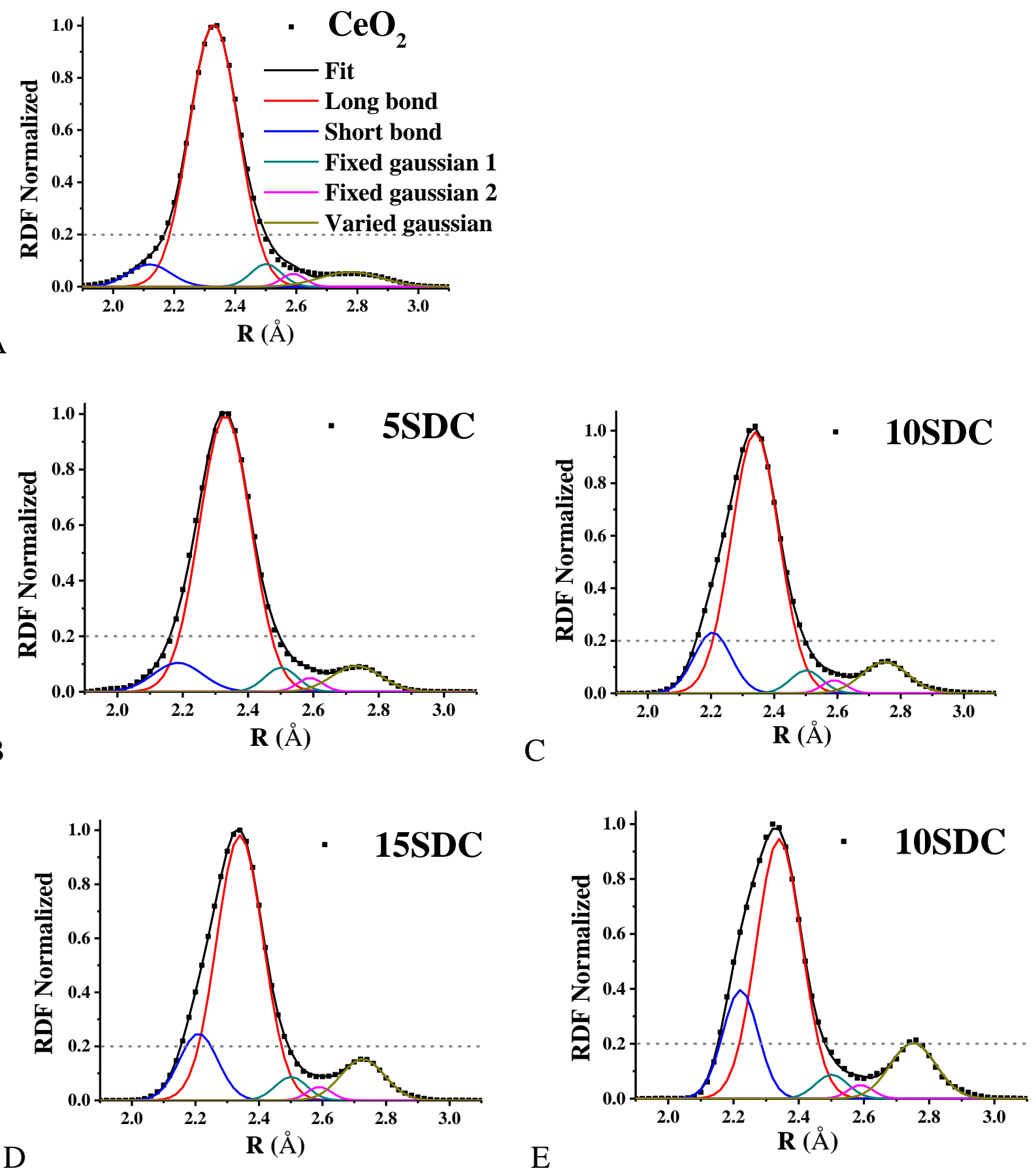

Figure S14: Bi-modal distribution Gaussian fits for $\mathrm{CeO}_{2}$ and $\mathrm{Sm}$ doped ceria films, for the 1NN RDFs of Ce. 